\title{
Pediatric Endocrinology in the Time of COVID-19: Considerations for the Rapid Implementation of Telemedicine and Management of Pediatric Endocrine Conditions
}

\author{
Molly O. Regelmanna Rushika Conroy ${ }^{b}$ Evgenia Gourgaric Anshu Gupta ${ }^{d}$ \\ Ines Guttmann-Bauman ${ }^{\mathrm{e}}$ Ryan Heksch ${ }^{f}$ Manmohan K. Kambojg Sowmya Krishnan ${ }^{\text {h }}$ \\ Amit Lahoti ${ }^{i}$ Kristal Matlock ${ }^{j}$ on behalf of the PES Drug and Therapeutics Committee and \\ Practice Management Committee

\begin{abstract}
aDivision of Pediatric Endocrinology and Diabetes, Children's Hospital at Montefiore, Albert Einstein School of Medicine, Bronx, NY, USA; 'Division of Pediatric Endocrinology, Baystate Children's Hospital, Springfield, MA,

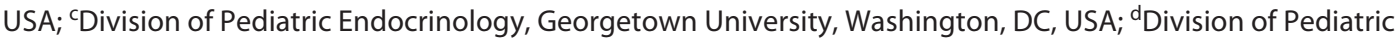
Endocrinology, Diabetes and Metabolism, Children's Hospital of Richmond at Virginia Commonwealth University,

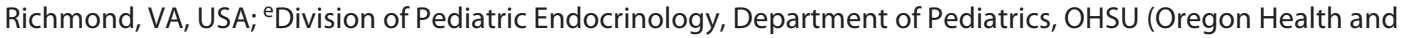
Science University), Portland, OR, USA; ${ }^{\mathrm{f} C e n t e r}$ for Diabetes and Endocrinology, Department of Pediatrics, Akron Children's Hospital, Akron, OH, USA; ${ }^{9}$ Division of Pediatric Endocrinology, Nationwide Children's Hospital at The Ohio State University, Columbus, $\mathrm{OH}, \mathrm{USA}^{\mathrm{h}}{ }^{\mathrm{h}}$ Division of Pediatric Diabetes and Endocrinology, University of Oklahoma Health Science Center, Oklahoma City, OK, USA; 'Division of Endocrinology, Department of Pediatrics, University of Tennessee Health Science Center, Memphis, TN, USA; 'Division of Pediatric Endocrinology, Medical University of South Carolina, Charleston, SC, USA
\end{abstract}

\section{Keywords}

Telemedicine · Coronavirus disease 2019 • Pediatric endocrinology $\cdot$ Diabetes

\begin{abstract}
Background: Pediatric endocrine practices had to rapidly transition to telemedicine care at the onset of the novel coronavirus disease 2019 (COVID-19) pandemic. For many, it was an abrupt introduction to providing virtual healthcare, with concerns related to quality of patient care, patient privacy, productivity, and compensation, as workflows had to change. Summary: The review summarizes the common adaptations for telemedicine during the pandemic with respect to the practice of pediatric endocrinology and discusses the benefits and potential barriers to telemedicine. Key
\end{abstract}

Messages: With adjustments to practice, telemedicine has allowed providers to deliver care to their patients during the COVID-19 pandemic. The broader implementation of telemedicine in pediatric endocrinology practice has the potential for expanding patient access. Research assessing the impact of telemedicine on patient care outcomes in those with pediatric endocrinology conditions will be necessary to justify its continued use beyond the COVID-19 pandemic.

(c) 2021 S. Karger AG, Basel

\section{Introduction}

Until recently, in the USA, telemedicine has had limited applications due to lack of payer acceptance. With the onset of the novel coronavirus disease 2019 (CO-

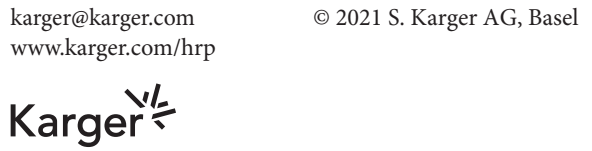


VID-19) pandemic, many pediatric endocrine practices have been forced to rapidly transition to virtual visits; this served as a practical solution to reduce risks for infection by allowing patients and families to access care from their homes. The implementation of telemedicine has led to positive experiences and acceptance by many patients, families, and providers. Telemedicine reduces costs of transportation, time missed from work and school, and anxiety felt by patients and families because they are seen in their familiar home environment [1-3]. Following the COVID-19 pandemic, it seems likely that telemedicine will be permanently integrated into clinical practice $[1,4]$. Most providers in the pediatric endocrinology community have experience reviewing blood glucose logs for diabetes over the phone or via patient portals, but many have limited experience with remote physical examinations and best practices for telemedicine. Even those who previously utilized video telemedicine prior to the pandemic had to adjust to patients being at their home, rather than in clinics with trained medical professionals available to obtain vital signs and anthropometric measurements. There are limited data to provide evidence for best practices with respect to telemedicine and the practice of pediatric endocrinology. We aim to summarize the considerations related to the broader implementation of telemedicine into pediatric endocrine practices and provide our expert opinion regarding processes for providing patient care.

\section{Practical Implementation of Telemedicine into Clinical Practice}

Effective implementation and reimbursement for telemedicine require Health Insurance Portability and Accountability Act (HIPAA)-compliant platforms (in the USA, HIPAA ensures the security of private patient medical information), availability of technology for providers and patients, and an understanding of payer requirements. The Centers for Medicare and Medicaid Services (CMS) issued an interim final rule on March 30, 2020, that extends temporary regulatory waivers to healthcare providers to facilitate safe and effective care; however, the duration of the waivers is unclear. The regulations aimed to increase hospital capacity, expand the healthcare workforce, improve access to telehealth services, and reduce the regulatory burden on providers. These regulations became retroactively applicable beginning on March 1, 2020. Although these changes are accepted by Medicare, private insurers are not mandated to adopt them. Areas relevant to endocrine practices include the following:

- Expansion of covered telehealth services

- Reducing or waiving beneficiary cost-sharing for telehealth and certain other services

- Coverage of remote monitoring services for new patients

- Coverage of telephone evaluation and management (E/M) services

- Waiving of the requirement for the face-to-face visit for patients with insulin pumps

- Simplification of the documentation requirements for E/M services delivered via telehealth

- Provision of additional flexibility to deliver Medicare Diabetes Prevention Program services [5]

Telehealth implementation requires a comprehensive understanding of eligibility, terminology, and billing. It is important to be aware of state- and institution-specific licensing requirements prior to implementation, as well as both insurance and malpractice coverage of the visits. Eligibility and documentation requirements differ for telemedicine visits according to their classification. Understanding of the requirements is essential for compliance with coding and billing. Virtual services include telehealth visits, virtual check-ins, and e-visits [6]. Until the COVID-19 pandemic, state medical licensure regulations limited some telehealth services that crossed state lines and included requirements for end-to-end HIPAA-compliant hardware and software. Historically, providers had to be licensed in the state the patient was in at the time of the visit, at least for new patient consultations. With the onset of the pandemic, CMS waived this requirement for Medicare patients. States could request a waiver for Medicaid patients, and the Department of Health and Human Services has requested states to modify licensure requirements to facilitate interstate practice, although this has only occurred to a limited degree. Because rules are changing quickly and may revert once the pandemic resolves, it will be important to remain informed and adjust practices accordingly [7] (Table 1).

Telemedicine encounters also require patients and families to have the resources to allow for successful visits. The introduction of telehealth has brought to the forefront concerns about patient privacy and security of communication platforms. HIPAA violation penalties against healthcare workers have been waived temporarily to allow for use of widely available video-calling services, such as FaceTime ${ }^{\circledR}$, Skype ${ }^{\circledR}$, Google Duo ${ }^{\circledR}$, and WhatsApp ${ }^{\circledR}$, but institutions appropriately continue to encourage use of HIPAA-compliant platforms, for example, Zoom 
Table 1. Classification of virtual services

\begin{tabular}{lccc}
\hline Virtual service, patient type & $\begin{array}{l}\text { Visit length, } \\
\text { min }\end{array}$ & $\begin{array}{l}\text { Billing } \\
\text { code }\end{array}$ & $\begin{array}{l}\text { Relative } \\
\text { value unit }\end{array}$ \\
\hline E-visit, established & $5-10$ & 99421 & 0 \\
& $11-20$ & 99422 & 0 \\
& $>21$ & 99423 & 0 \\
\hline Remote evaluation of image/video, established & Not applicable & G2010 & 0.18 \\
\hline Virtual check-in, established & 5 & G2012 & 0.25 \\
\hline Phone visit, new or established & $5-10$ & 99441 & 0.25 \\
& $11-20$ & 99442 & 0.5 \\
\hline Telehealth (video), new ${ }^{\text {a }}$ & $21-30$ & 99443 & 0.75 \\
\hline Telehealth (video), established & 10 & 99201 & 0.48 \\
& 20 & 99202 & 0.93 \\
& 30 & 99203 & 1.42 \\
& 45 & 99204 & 2.43 \\
& 60 & 99205 & 3.17 \\
\hline
\end{tabular}

a Length of visit is used based on counseling, discussion, and/or coordination of care being $>50 \%$ of the visit. Visits may also be billed based on complexity. Table modified from Smith et al. [6], with permission from Elsevier.

Health $^{\circledR}$, Doximity ${ }^{\circledR}$, Amwell $^{\circledR}$, and MyChart ${ }^{\circledR}$ (The list of applications, both HIPAA-compliant and nonHIPAA-compliant, is not intended to be inclusive, but to provide examples of applications in current use. Use of various platforms and disclaimer information is partly dictated by Medicare and by individual institutional guidelines.). Table 2 highlights practical considerations for telemedicine visits.

\section{Pediatric Diabetes Mellitus}

The COVID-19 pandemic has presented unique challenges in the care of pediatric patients with diabetes in the inpatient setting, outpatient clinics, and in the application of current screening recommendations for ongoing care.

\section{New-Onset Diabetes Mellitus and Inpatient Diabetes}

Management

For patients with new-onset diabetes mellitus, especially those presenting in diabetic ketoacidosis (DKA) or
Table 2. Practical necessities for successful telemedicine encounters

Stable and affordable internet connection

Appropriate room lighting

Camera positioned on patient

Both patient and caregiver present for appointment ${ }^{\mathrm{a}}$

Established private space for adolescents to answer confidential questions

Follow-up communication of after visit summary Patient portal Secure e-mail

Access to testing facilities

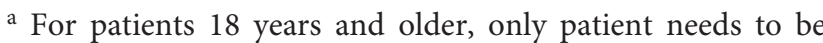
present.

in institutions where all new-onset diabetes education is done in an inpatient setting, teams faced several barriers with respect to safety, access, and patient-centeredness [8, 
9]. Often the inpatient teams comprised multiple members, including but not limited to trainees, nurses, diabetes educators, dietitians, and social workers, thus increasing exposure to and from multiple personnel. One of the initial modifications for family-centered team rounds has been to limit the number of team members entering the patient's room. Aside from the initial history, physical examination, and initial discussion with the endocrinologists, the roles of the diabetes care team, which includes diabetes educators, dietitians, and social workers, typically involve prolonged face-to-face education and discussion time. These processes are more complex to modify and often rely on individual institutional guidelines. The use of video platforms to complete some of the tasks has been implemented at many institutions, although some do not allow telehealth for inpatient care, and the efficacy of telemedicine for new-onset diabetes education is unknown at this time.

Restrictions on the number of family members (often only one caregiver) allowed with each child either admitted to the hospital or visiting the clinic further complicate care and discharge planning. Diabetes education most often is a "family affair"; multiple family members and caregivers typically require diabetes education in order to care for the child. Consequently, a limitation on the number of visitors requires additional time for diabetes team members to set up virtual or outpatient clinic trainings. Hospital- and clinic-issued tablets and virtual meetings have been used by physicians and diabetes team members to connect to other family members while providing inpatient face-to-face diabetes education $[9,10]$. Finally, the use of continuous glucose monitors (CGM) in the inpatient setting has been recognized as an alternative to reduce the time spent with patients during the COVID-19 pandemic $[11,12]$. However, the safe implementation of CGM systems in the inpatient setting might be challenging and requires the creation of CGM protocols by hospitals and availability of trained personnel [12].

\section{Remote Outpatient Monitoring and Televisits}

Remote monitoring technologies such as wireless standalone glucose meters, CGM, and insulin pumps integrated with CGM can transmit data via a cloud-based platform to a website, a patient's smart phone, or to a provider's clinic $[13,14]$. During the pandemic, these technologies have played a central role in ensuring access to remote healthcare for children with diabetes $[8,14,15]$. Simultaneously, the technology has brought forth challenges with respect to the remote training of patients and caregivers and led to new processes for communication with patients, which require consideration for data privacy and confidentiality. In addition, clinic workflow has had to change to account for the transition from in-person glucose meter, CGM, and insulin pump downloads to telehealth uploads $[8,14]$.

In an ideal setting, centers with a dedicated diabetes clinic can have staff (e.g., medical assistants, nurses, and diabetes educators) assume the role of connecting and transmitting patient data to the provider prior to and after an appointment. As an example of a process followed by some centers, patients were contacted by the clinic team member to check if they had a device compatible with software, such as Dexcom Clarity ${ }^{\circledR}$, Glooko/Diasend $^{\circledR}$, Medtronic CareLink ${ }^{\circledR}$, t:connect ${ }^{\circledR}$, and Tidepool ${ }^{\circledR}$. Clinic staff provided technological support to patients who had a device that was not yet synchronized with the clinic. Approximately 2 business days before the visit, the patient is instructed to "upload" or "synchronize" their device. The data are then downloaded by the diabetes support staff, and the report was incorporated into the patient's chart. Patients who use an independent application or a non-cloud compatible device are instructed on how to download a report and send to clinic by various methods, including an electronic secure portal for enrolled patients and fax/e-mail for others. For patients with limited English proficiency and/or no access to the above mentioned resources, the diabetes educators obtain data via phone for a 3-5-day period and provide that via a "logbook" to the provider. In centers utilizing a shared model of staffing or providers in solo practice, there is a significant variation in delegation of this support role and often the burden for obtaining records falls on the provider. Availability of training in these technologies for ancillary staff and patients is vital to sustaining remote monitoring programs for diabetes during and after the pandemic $[13,16,17]$. Integration of remote monitoring technology into modern electronic health records may help mitigate privacy and confidentiality concerns over transmission of data via non-HIPAA approved modalities, such as e-mail.

Telemedicine visits for pediatric and adolescent patients with diabetes pose several specific challenges, but also can provide an opportunity for providers to better understand social concerns in patients' home environments. Anecdotally, adolescent patients may be more open to engaging with video technology, although ensuring their privacy during interviewing may be more difficult. Sending questionnaires, such as a depression screen, either through a secure patient portal or e-mail prior to the visit may help facilitate visits, but safety procedures 
need to be put in place to ensure timely follow-up of concerning responses [18]. Home medications and supplies can be checked via video. Teaching hands-on skills, such as injections and glucose monitoring, may be more difficult without a provider's hand to guide the patient and caregiver. Physical examinations specifically to assess for neuropathy and lipohypertrophy at insulin injection sites, as well as pubertal examinations and blood pressure monitoring (see discussions below), are also likely to be limited by telehealth capabilities and should be prioritized when patients are evaluated during in-person visits.

\section{Outpatient Screening for Comorbidities of Diabetes}

Diabetic Retinopathy Screening

For those with type 1 diabetes mellitus, the American Diabetes Association (ADA) recommends that after the initial screening (recommended at age 10 years or after puberty, whichever occurs earlier, in patients younger than 18 years with diabetes for 3-5 years), repeat examinations for diabetic retinopathy are recommended annually, but at the discretion of an eye care professional, it may be reasonable to check every 2 years [19]. The International Society for Pediatric and Adolescent Diabetes (ISPAD) recommends screening for retinopathy starting from 11 years with a diabetes duration of 2-5 years. The ISPAD guidelines also support retinal exams every other year in those with diabetes for $<10$ years and without risk factors (risk factors were defined as poor diabetes control, high blood pressure, dyslipidemia, and high body mass index) [20]. Screening is recommended at diagnosis and annually for those with type 2 diabetes $[19,20]$. Digital retinal exams by telemedicine have been used to evaluate adults for diabetic retinopathy and could be a cost-effective alternative in youth with diabetes, but still require access to the technology to image the retina [21]. Some evidence suggests frequent eye examinations might not be universally necessary in youth $<18$ years of age; thus, in the setting of a pandemic, it may be reasonable to consider deferring the routine screening examination until local infection rates are sufficiently low [22].

\section{Blood Pressure Screening}

The ADA and the American Academy of Pediatrics recommend screening youth with diabetes for hypertension at every visit $[19,23,24]$. ISPAD guidelines recommend blood pressure monitoring "at least annually" [20]. Telemedicine has been used for remote monitoring of home blood pressure with the use of certain devices, but their utility to screen asymptomatic youth with diabetes is unclear [25]. Ambulatory 24-h remote blood pressure monitoring could be used to screen for hypertension in youth with diabetes mellitus at high risk for cardiovascular disease. Other options include in-person drop-in visits to obtain blood pressure along with anthropometric data that can be evaluated during the virtual visit, but this process still requires staff and time to clean equipment for infection control.

\section{Blood and Urine Screening}

For patients using CGM, the Glucose Management Indicator is an acceptable alternative to hemoglobin A1c (HbAlc) that can provide information for personalized diabetes management [26]. In a pandemic setting, HbA1c would be more helpful for children who are not adherent with blood glucose monitoring and are not using CGM. Screening tests for celiac disease, thyroid dysfunction, and hyperlipidemia could also be deferred in children who had a normal examination in the last 2 years and continue to be asymptomatic [19]. ADA guidelines recommend annual assessment of urine albumin/creatinine ratios in youth who have had type 1 diabetes for at least 5 years and are either pubertal or $>10$ years of age, whichever is earlier [19]. ISPAD guidelines suggest screening for albuminuria starting at age 11 years in those with a diabetes duration of 2-5 years [20]. A urine albumin/creatinine ratio test is recommended at diagnosis and annually for those with type 2 diabetes mellitus [19, 20,27].

\section{Pediatric Endocrine Care}

Comprehensive assessment of pediatric endocrine conditions requires evaluation of anthropometrics and laboratory/radiologic assessments in addition to detailed histories and physical examinations. Prior studies show successful use of telemedicine for pediatric obesity, but it can be challenging to translate this process into telemedicine for other endocrine conditions [28-30]. Requesting growth charts from the referring provider along with ordering targeted laboratory and radiologic assessment prior to the visit assists in efficient use of telemedicine and in triaging those who require in-person evaluation. This requires education of scheduling personnel and clinical staff on recommended protocols, identification of local laboratory facilities, urgency of evaluation, and required information to appropriately evaluate each condition. For example, when evaluating a child with concerns for hyperthyroidism, obtaining prior thyroid function tests, vital signs from a recent visit to the referring provider, and directing patients to have any additional laboratory 
Table 3. Telemedicine considerations for common pediatric endocrine conditions [35-45]

\begin{tabular}{|c|c|c|c|}
\hline $\begin{array}{l}\text { Endocrine } \\
\text { condition }\end{array}$ & Assessment prior to visit & Management challenges & Management opportunities \\
\hline Thyroid disease & $\begin{array}{l}\text { Virtual assessment feasible? } \\
\text { New: yes } \\
\text { Return: yes } \\
\text { Information to obtain: growth charts, resting heart rate, BP, } \\
\text { medication refill history, laboratory evaluation, and thyroid } \\
\text { ultrasound }\end{array}$ & $\begin{array}{l}\text { Thyroid (and eye) exam limited to visual inspection } \\
\text { Complete assessment is difficult without laboratory } \\
\text { evaluation } \\
\text { Patients with thyroid cancer require multidisciplinary } \\
\text { consultations, counseling, or psychotherapy 35] }\end{array}$ & $\begin{array}{l}\text { Teach thyroid self-exam to patients } \\
\text { Explore development of TSH assays using filter paper- } \\
\text { dried blood spot for in-home blood sampling by patient/ } \\
\text { parent [36] } \\
\text { Consider developing a multidisciplinary virtual visit where } \\
\text { specialists and ancillary staff can collaborate }\end{array}$ \\
\hline $\begin{array}{l}\text { Amenorrhea/ } \\
\text { PCOS }[37,38]\end{array}$ & $\begin{array}{l}\text { Virtual assessment feasible? } \\
\text { New: yes with in-person examination if indicated } \\
\text { Return: yes } \\
\text { Information to obtain: } \mathrm{BMI} \text { and BP }\end{array}$ & $\begin{array}{l}\text { Reduced access to treatment for disordered eating } \\
\text { PCOS features can overlap with normal features of } \\
\text { adolescence }\end{array}$ & $\begin{array}{l}\text { Virtual RD visit for low BMI or obesity } \\
\text { Use of the Ferriman-Gallwey score to assess hirsutism, an } \\
\text { alternative indicator of hyperandrogenism in adolescents }\end{array}$ \\
\hline Delayed puberty & $\begin{array}{l}\text { Virtual assessment feasible? } \\
\text { New: no } \\
\text { Return: yes with in-person exam if indicated } \\
\text { Information to obtain: growth charts and laboratory } \\
\text { evaluation }\end{array}$ & $\begin{array}{l}\text { Difficult to distinguish constitutional delay from other } \\
\text { etiologies } \\
\text { IM testosterone administration requires visit to healthcare } \\
\text { provider if family unable to administer at home }\end{array}$ & $\begin{array}{l}\text { Utilize bone age, ultrasensitive LH/FSH, and karyotype } \\
\text { and consider inhibin B and anti-Müllerian hormone to } \\
\text { help differentiate etiology }[39,40] \\
\text { Utilize non-IM testosterone or teach caregiver } \\
\text { administration for IM or subcutaneous injection therapy } \\
\text { [41] }\end{array}$ \\
\hline Precocious puberty & $\begin{array}{l}\text { Virtual assessment feasible? } \\
\text { New: no } \\
\text { Return: yes with in-person examination if indicated } \\
\text { Information to obtain: growth charts, medication refill or } \\
\text { implant insertion history, and laboratory evaluation [42] }\end{array}$ & $\begin{array}{l}\text { Self-exams not reliable }[33,34] \\
\text { No well-studied alternative for laboratory testing } \\
\text { Potentially more challenging to remove histrelin implant if } \\
\text { left in situ for }>1 \text { year }[42]\end{array}$ & $\begin{array}{l}\text { Teach caregiver administration of Depot-leuprolide } \\
\text { acetate or obtain visiting nurse support } \\
\text { Histrelin implant has shown efficacy for up to } 2 \text { years after } \\
\text { insertion [42] } \\
\text { Use longer-acting 6-month injectable GnRH agonists: } \\
\text { leuprolide acetate (newer preparation) or triptorelin }\end{array}$ \\
\hline Short stature [43] & $\begin{array}{l}\text { Virtual assessment feasible? } \\
\text { New: yes if }>2 \text { years of age and less than adolescent age, } \\
\text { with in-person exam if indicated } \\
\text { Return: yes with in-person exam if indicated } \\
\text { Information to obtain: growth charts, medication refill } \\
\text { history, and laboratory evaluation }\end{array}$ & $\begin{array}{l}\text { Obtaining accurate height and weight may be difficult, } \\
\text { especially in an uncooperative child } \\
\text { Obtaining bone age image from an external facility }\end{array}$ & $\begin{array}{l}\text { Utilize in-person focused examination and measurements } \\
\text { for children }<2 \text { years of age } \\
\text { Consider scheduling in-office measurement of height and } \\
\text { weight before or after completion of virtual visit } \\
\text { Utilize facilities able to upload imaging to shared radiology } \\
\text { systems or request parents provide CD }\end{array}$ \\
\hline $\begin{array}{l}\text { Obesity/ } \\
\text { abnormal weight } \\
\text { gain }[28,29]\end{array}$ & $\begin{array}{l}\text { Virtual assessment feasible? } \\
\text { New: yes } \\
\text { Return: yes } \\
\text { Information to obtain: growth charts, BMI, BP, and } \\
\text { laboratory evaluation }\end{array}$ & Limited access to BP and weight measurement & $\begin{array}{l}\text { Prescribe home blood pressure monitor and scale } \\
\text { Virtual RD assessment }\end{array}$ \\
\hline $\begin{array}{l}\text { Gender dysphoria } \\
{[44]}\end{array}$ & $\begin{array}{l}\text { Virtual assessment feasible? } \\
\text { New: yes with in-person examination if indicated } \\
\text { Return: yes with in-person examination if indicated } \\
\text { Information to obtain: documentation from mental health } \\
\text { provider evaluation if available }\end{array}$ & $\begin{array}{l}\text { Caregiver uncomfortable with in-person visits } \\
\text { Physical examination needed in some cases to determine } \\
\text { onset of puberty } \\
\text { Behavioral health may be unavailable virtually } \\
\text { Confidentiality/privacy at home } \\
\text { Potentially more challenging to remove histrelin implant if } \\
\text { left in situ for }>1 \text { year [42] }\end{array}$ & $\begin{array}{l}\text { Consider morning } \mathrm{LH} / \mathrm{T} / \mathrm{E} 2 \text { measurement as alternative } \\
\text { for determining onset of puberty } \\
\text { Medications can be initiated virtually } \\
\text { Collaborate with procedure units and pediatric surgery to } \\
\text { coordinate GnRH agonist therapy. Histrelin implant has } \\
\text { shown efficacy for up to } 2 \text { years after injection [ } 42] \\
\text { Use of } 6 \text {-month injectable GnRH agonists }\end{array}$ \\
\hline $\begin{array}{l}\text { Congenital adrenal } \\
\text { hyperplasia [45] }\end{array}$ & $\begin{array}{l}\text { Virtual assessment feasible? } \\
\text { New: no } \\
\text { Return: yes with in-person exam if indicated } \\
\text { Information to obtain: growth charts, medication refill } \\
\text { history, laboratory evaluation (prior to morning dose), BP, } \\
\text { heart rate, and BMI }\end{array}$ & $\begin{array}{l}\text { Limited access to BP, heart rate, weight, and height } \\
\text { measurements }\end{array}$ & $\begin{array}{l}\text { Teach parents how to measure pulse and prescribe home } \\
\text { blood pressure monitor } \\
\text { Dose adjustments can be done virtually if height and } \\
\text { weight are able to be obtained }\end{array}$ \\
\hline
\end{tabular}

BMI, body mass index; BP, blood pressure; E2, estradiol; FSH, follicle-stimulating hormone; GnRH, gonadotropin-releasing hormone; IM, intramuscular; LH, luteinizing hormone; PCOS, polycystic ovarian syndrome; RD, registered dietitian; T, testosterone; TSH, thyroid-stimulating hormone.

testing prior to the visit can drastically improve the efficiency of a telemedicine visit.

Clinicians can also utilize techniques to improve physical assessment during visits. Parent-measured height and weight is an alternative when in-office measurements are not feasible; parents can be provided with instructions on how to obtain measurements to streamline this process $[31,32]$. Pubertal and genital examinations via video are not recommended. Pubertal examinations present a significant challenge; a recent meta-analysis found selfassessment of puberty is most accurate when identifying Tanner stage 1 for pubic hair for both sexes, Tanner stage 1 for breast development, and Tanner stage 5 for male pubic hair. Accuracy was diminished for the stages inbetween $[33,34]$. Families may have access to a blood pressure monitor and could measure heart rate manually or via home device if prompted. In addition, disease-specific symptom checklists can be created in the EMR and completed by families prior to their visit to streamline the process.

During telemedicine visits, history-taking remains essentially unchanged compared to in-person encounters. However, sensitive information (i.e., drug use, libido, and sexual history) may be difficult to acquire confidentially. Establishing a routine for adolescents to have a few minutes to answer confidential questions alone in the room 
may help. At the provider's discretion, an in-person visit should be requested for a focused examination when evaluating a thyroid nodule, assessing pubertal stage, clitoral size, genitourinary anomalies, and other findings that cannot be effectively assessed virtually. Table 3 details opportunities and challenges in the management and evaluation of common endocrine conditions when access to in-person visits is limited.

\section{Conclusion}

Telemedicine has been an essential tool during the COVID-19 pandemic, as it has allowed providers to deliver care to their patients, albeit with some compromises and adjustments. The broad implementation of telemedicine has the potential for expanding access to care and improvement in the management of chronic conditions. Lessons learned during the pandemic should be used as the first step to address the long-term use of telemedicine practices in specific, well-defined scenarios. Research assessing the impact of telemedicine on the care of pediatric endocrinology conditions will be necessary to justify its continued use beyond the COVID-19 pandemic [15]. Institutional policies and procedures will need to be updated to address patient privacy and provider workflow as telemedicine is likely to remain part of pediatric endocrine care. Finally, continued adequate payer reimbursement for care coordination and remote monitoring will be necessary in order to assure long-term viability of telemedicine practices in pediatric endocrinology.

\section{Acknowledgements}

The authors thank the members of the Board of Directors and the larger Drug and Therapeutics Committee and Practice Management Committee of the Pediatric Endocrine Society for thoughtful review and constructive comments of the manuscript.

\section{Conflict of Interest Statement}

The authors have no conflicts of interest to declare.

\section{Funding Sources}

Support of this publication was provided by the Pediatric Endocrine Society.

\section{Author Contributions}

The concept for the manuscript was discussed as part of a larger Drug and Therapeutics Committee meeting. M.R. formally proposed the concept to the Board of Directors of the Pediatric Endocrine Society. All listed authors participated in a discussion of the outline of the manuscript, contributed original sections of text and/or tables of the initial draft, and provided review and edits of subsequent drafts. M.R. prepared the final manuscript. All the listed authors read and approved the final manuscript. The Drug and Therapeutics Committee and the Practice Management Committee, as well as the Board of Directors of the Pediatric Endocrine Society, had the opportunity to review and comment on the manuscript.

\section{References}

1 Burke BL, Hall RW; Section on Telehealth Care. Telemedicine: pediatric applications. Pediatrics. 2015 Jul;136(1):e293-308.

2 Ray KN, Ashcraft LE, Mehrotra A, Miller E, Kahn JM. Family perspectives on telemedicine for pediatric subspecialty care. Telemed J E Health. 2017;23(10):852-62.

3 Casares M, Wombles C, Skinner HJ, Westerveld M, Gireesh ED. Telehealth perceptions in patients with epilepsy and providers during the COVID-19 pandemic. Epilepsy Behav. 2020 Sep;112:107394.

4 Cabana MD, Menard-Livingston L. Will telemedicine be the Blockbuster or Netflix of healthcare? Medpage Today. 2020. Available from: https://www.medpagetoday.com/practicemanagement/telehealth/87662.
5 Endocrine Society [Internet]. Summary of Key Provisions of the COVID-19 Public Health Emergency Interim Final Rule Relevant to Endocrinology: Endocrine Society, Hormone Science to Health, document prepared for the Endocrine Society by Cavarocchi Ruscio Dennis Associates. [cited 2020 Aug 28]. Available from: https://www.endocrine. org/-/media/endocrine/files/membership/ summary-of-cms-rule-42020.pdf.

6 Smith WR, Atala AJ, Terlecki RP, Kelly EE, Matthews CA. Implementation guide for rapid integration of an outpatient telemedicine program during the COVID-19 pandemic. J Am Coll Surg. 2020 Aug;231(2):216e2.

7 Cohen BH, Busis NA, Ciccarelli L. Coding in the world of COVID-19: non-face-to-face evaluation and management care. Continuum. 2020 Jun;26(3):785-98.
8 Garg SK, Rodbard D, Hirsch IB, Forlenza GP. Managing new-onset type 1 diabetes during the COVID-19 pandemic: challenges and opportunities. Diabetes Technol Ther. 2020 Jun; 22(6):431-9.

9 Jones MS, Goley AL, Alexander BE, Keller SB, Caldwell MM, Buse JB. Inpatient transition to virtual care during COVID-19 pandemic. Diabetes Technol Ther. 2020 Jun;22(6):444-8.

10 Peters AL, Garg SK. The silver lining to COVID-19: avoiding diabetic ketoacidosis admissions with telehealth. Diabetes Technol Ther. 2020 Jun;22(6):449-53.

11 Singh LG, Satyarengga M, Marcano I, Scott WH, Pinault LF, Feng Z, et al. Reducing inpatient hypoglycemia in the general wards using real-time continuous glucose monitoring: the glucose telemetry system. a randomized clinical trial. Diabetes Care. 2020 Nov;43(11): 2736-43. 
12 Korytkowski M, Antinori-Lent K, Drincic A, Hirsch IB, McDonnell ME, Rushakoff R, et al. A pragmatic approach to inpatient diabetes management during the COVID-19 pandemic. J Clin Endocrinol Metab. 2020;105(9): dgaa342.

13 Philip M, Bergenstal RM, Close KL, Danne T, Garg S, Heinemann L, et al. The digital/virtual diabetes clinic: the future is non-recommendations from an international panel on diabetes digital technologies introduction. Diabetes Technol Ther. 2020 Sep 28.

14 De Guzman KR, Snoswell CL, Taylor ML, Senanayake B, Haydon HM, Batch JA, et al. A systematic review of pediatric telediabetes service models. Diabetes Technol Ther. 2020 Aug;22(8):623-38.

15 D’Anunzio G, Maffeis C, Cherubini V, Rabbone I, Scaramuzza A, Schiaffini R, et al. Caring for children and adolescents with type 1 diabetes mellitus: Italian Society for Pediatric Endocrinology and Diabetology (ISPED) statements during COVID-19 pandemia. Diabetes Res Clin Pract. 2020 Aug 20;168: 108372.

16 Whittaker SL, Adkins S, Phillips R, Jones J, Horsley MA, Kelley G. Success factors in the long-term sustainability of a telediabetes programme. J Telemed Telecare. 2004;10(2): 84-8.

17 Su D, Michaud TL, Estabrooks P, Schwab RJ, Eiland LA, Hansen G, et al. Diabetes management through remote patient monitoring: the importance of patient activation and engagement with the technology. Telemed J E Health. 2019 Oct;25(10):952-9.

18 Evans YN, Golub S, Sequeira GM, Eisenstein E, North A. Using telemedicine to reach adolescents during the COVID-19 pandemic. J Adolesc Health. 2020 Oct;67(4):469-71.

19 American Diabetes Association. 13. Children and adolescents: standards of medical care in diabetes-2020. Diabetes Care. 2020 Jan; 43(Suppl 1):S163-82.

20 Donaghue KC, Marcovecchio ML, Wadwa RP, Chew EY, Wong TY, Calliari LE, et al. ISPAD clinical practice consensus guidelines 2018: microvascular and macrovascular complications in children and adolescents. Pediatr Diabetes. 2018 Oct;19(Suppl 27):262-74.

21 Avidor D, Loewenstein A, Waisbourd M, Nutman A. Cost-effectiveness of diabetic retinopathy screening programs using telemedicine: a systematic review. Cost Eff Resour Alloc. 2020 April;18:16.

22 Gubitosi-Klug RA, Bebu I, White NH, Malone J, Miller R, Lorenzi GM, et al. Screening eye exams in youth with type 1 diabetes under 18 years of age: once may be enough? Pediatr Diabetes. 2019 Sep;20(6):743-9.
23 Flynn JT, Kaelber DC, Baker-Smith CM, Blowey D, Carroll AE, Daniels SR, et al. Subcommittee on screening management of high blood pressure in children. Clinical practice guideline for screening and management of high blood pressure in children and adolescents. Pediatrics. 2017 Sep;140(3):e20171904.

24 de Ferranti SD, Steinberger J, Ameduri R, Baker A, Gooding H, Kelly AS, et al. Cardiovascular risk reduction in high-risk pediatric patients: a scientific statement from the American Heart Association. Circulation. 2019 Mar;139(13):e603-34.

25 Omboni S, Ferrari R. The role of telemedicine in hypertension management: focus on blood pressure telemonitoring. Curr Hypertens Rep. 2015 Apr;17(4):535.

26 Bergenstal RM, Beck RW, Close KL, Grunberger G, Sacks DB, Kowalski A, et al. Glucose management indicator (GMI): a new term for estimating $\mathrm{A} 1 \mathrm{C}$ from continuous glucose monitoring. Diabetes Care. 2018 Nov;41(11): 2275-80.

27 Zeitler P, Arslanian S, Fu J, Pinhas-Hamiel O, Reinehr T, Tandon N, et al. ISPAD clinical practice consensus guidelines 2018: type 2 diabetes mellitus in youth. Pediatr Diabetes. 2018 Oct;19(Suppl 27):28-46.

28 Davis AM, Sampilo M, Gallagher KS, Dean K, Saroja MB, Yu Q, et al. Treating rural paediatric obesity through telemedicine vs. telephone: outcomes from a cluster randomized controlled trial. J Telemed Telecare. 2016 Mar;22(2):86-95.

29 Davis AM, James RL, Boles RE, Goetz JR, Belmont J, Malone B. The use of TeleMedicine in the treatment of paediatric obesity: feasibility and acceptability. Matern Child Nutr. 2011 Jan;7(1):71-9.

30 Schiel R, Beltschikow W, Radón S, Kramer G Schmiedel R, Berndt RD, et al. Long-term treatment of obese children and adolescents using a telemedicine support programme. J Telemed Telecare. 2008;14(1):13-6.

31 Ohri-Vachaspati P, Acciai F, DeLia D, Lloyd K, Yedidia MJ. Accuracy of parent-measured and parent-estimated heights and weights in determining child weight status. JAMA Pediatr. 2019 Jun;173(8):1-3.

32 Center for Disease Control Public Health Media Library [Internet]. Measuring Children's Height and Weight Accurately At Home. [cited Sept 4, 2020]. Available from: https://www. cdc.gov/healthyweight/assessing/bmi/childrens_bmi/measuring_children.html/ \#Height.

33 Campisi SC, Marchand JD, Siddiqui FJ, Islam M, Bhutta ZA, Palmert MR. Can we rely on adolescents to self-assess puberty stage? A systematic review and meta-analysis. J Clin Endocrinol Metab. 2020 Aug;105(8):dgaa135.

34 Rasmussen AR, Wohlfahrt-Veje C, Tefre de Renzy-Martin K, Hagen CP, Tinggaard J, Mouritsen A, et al. Validity of self-assessment of pubertal maturation. Pediatrics. 2015 Jan; 135(1):86-93.
35 Gibelli G, Gibelli B, Nani F. Thyroid cancer: possible role of telemedicine. Acta Otorhinolaryngol Ital. 2008 Dec;28(6):281-6.

36 Hofman LF, Foley TP Jr, Henry JJ, Naylor EW. Assays for thyroid-stimulating hormone using dried blood spotted filter paper specimens to screen for hypothyroidism in older children and adults. J Med Screen. 2003;10(1): 5-10.

37 Goodman NF, Cobin RH, Futterweit W, Glueck JS, Legro RS, Carmina E. American Association of Clinical Endocrinologists (AACE); American College of Endocrinology (ACE); Androgen Excess and PCOS Society. American Association of Clinical Endocrinologists, American College of Endocrinology, and Androgen Excess and PCOS Society disease state clinical review: guide to the best practices in the evaluation and treatment of polycystic ovary syndrome: part 2. Endocr Pract. 2015 Dec;21(12):1415-26.

38 Kansra AR, Menon S. PCOS: perspectives from a pediatric endocrinologist and a pediatric gynecologist. Curr Probl Pediatr Adolesc Health Care. 2013 May-Jun;43(5):104-13.

39 Rohayem J, Nieschlag E, Kliesch S, Zitzmann $\mathrm{M}$, Inhibin B. Inhibin B, AMH, but not INSL3, IGF1 or DHEAS support differentiation between constitutional delay of growth and puberty and hypogonadotropic hypogonadism. Andrology. 2015 Sep;3(5):882-7.

40 Harrington J, Palmert MR. Clinical review: distinguishing constitutional delay of growth and puberty from isolated hypogonadotropic hypogonadism: critical appraisal of available diagnostic tests. J Clin Endocrinol Metab. 2012 Sep;97(9):3056-67.

41 Wei C, Crowne EC. Recent advances in the understanding and management of delayed puberty. Arch Dis Child. 2016 May;101(5): 481-8.

42 Lewis KA, Goldyn AK, West KW, Eugster EA. A single histrelin implant is effective for 2 years for treatment of central precocious puberty. J Pediatr. 2013 Oct;163(4):1214-6.

43 Grote FK, Oostdijk W, De Muinck KeizerSchrama SM, van Dommelen P, van Buuren S, Dekker FW, et al. The diagnostic work up of growth failure in secondary health care; an evaluation of consensus guidelines. BMC Pediatr. 2008 May;8:21.

44 Hembree WC, Cohen-Kettenis PT, Gooren L, Hannema SE, Meyer WJ, Murad MH, et al Endocrine treatment of gender-dysphoric/ gender-incongruent persons: an Endocrine Society clinical practice guideline. J Clin Endocrinol Metab. 2017 Nov;102(11):3869-903.

45 Speiser PW, Arlt W, Auchus RJ, Baskin LS, Conway GS, Merke DP, et al. Congenital adrenal hyperplasia due to steroid 21-hydroxylase deficiency: an Endocrine Society clinical practice guideline. J Clin Endocrinol Metab. 2018 Nov; 103(11):4043-88 